\title{
Identification of Chromobacterium violaceum: Pigmented and Non-pigmented Strains
}

\author{
By R. SIVENDRA AND H. S. LO \\ Veterinary Research Institute, Ipoh, Malaysia \\ AND K. T. LIM \\ Regional Veterinary Diagnostic Laboratory, Petaling Jaya, Malaysia
}

(Received 30 September 1974; revised 20 April 1975)

\begin{abstract}
SUMMARY
The classification and, therefore, identification of Chromobacterium violaceum has been based upon its ability to produce a violet pigment. Although the organism may yield non-pigmented variants when subcultured on artificial media, the isolation of non-pigmented strains from pathological tissues or from nature had not been reported. With a method established for the identification of $C$. violaceum regardless of violet pigmentation, non-pigmented strains were isolated from nature. The presence of non-pigmented strains of $C$. violaceum in nature is of significance to taxonomy and clinical bacteriology. Pigmentation cannot be held as an essential characteristic of the definition of the genus Chromobacterium and gives credence to the suspicion of Sneath $(1960,1966)$ that the genus is not a natural one. Non-pigmented strains may have been isolated from clinical material but wrongly identified as belonging to other genera of non-pigmented Gram-negative bacilli and regarded as not being pathogenic.
\end{abstract}

\section{INTRODUCTION}

Identification of Chromobacterium violaceum has been based largely upon its unique violet pigmentation. In most laboratories tests such as Gram's staining, motility and some biochemical reactions were also done before conclusive identification was made:

Pigmented strains of $C$. violaceum may yield non-pigmented variants when subcultured on artificial media. However, there have been no reports of the isolation of non-pigmented strains directly from clinical material or from nature, possibly because the production of pigment has been held essential for identification (Leifson, I956; Sneath, I956a,c, 1960; Bergey's Manual of Determinative Bacteriology, I957; Judicial Commission, I958).

Sneath (1960) excluded non-pigmented strains of Chromobacterium as he had adopted pigmentation as part of his working definition of the genus. Sneath (Sneath et al. 1953; Sneath, I960, 1966), however, did not discount the possibility of a taxonomic relationship between Chromobacterium and non-pigmented forms and suggested that the genus is probably not a natural one. He concluded that if strains were faintly pigmented or lost their capacity to pigment, it would be almost impossible to identify them and they might be associated with other genera such as Aeromonas, Vibrio, Pseudomonas or Agrobacterium.

In the present study, we sought to determine the characteristics of $C$. violaceum and nonpigmented variants, to establish methods for the identification of the genus regardless of pigmentation, and then to use these characteristics to isolate non-pigmented strains from ponds. 
Table I. Sources of strains

\begin{tabular}{|c|c|c|c|}
\hline Strain & Source & Place & Year \\
\hline \multicolumn{4}{|c|}{ Pigmented strains } \\
\hline 874 & Local Indian dairy, cattle $\dagger$ & Kluang, Malaysia & 1970 \\
\hline 916 & Gibbont & Kuching, Malaysia & 1970 \\
\hline $609 *$ & Pond water & Sungei Buloh, Malaysia & 1972 \\
\hline $886^{*}$ & Pond water & Kluang, Malaysia & 1972 \\
\hline 17 & Jersey, calf $\dagger$ & Kluang, Malaysia & I 973 \\
\hline $76^{*}$ & Gibbon $\dagger$ & Kuantan, Malaysia & 1973 \\
\hline MDS9* & Santa Gertrudis, cattle $\dagger$ & Serdang, Malaysia & 1973 \\
\hline 510 & Lake water & Jakarta, Indonesia & 1973 \\
\hline $25^{*}$ & Ungka & Malacca, Malaysia & 1974 \\
\hline $617^{*}$ & Pond water & Behrang, Malaysia & 1974 \\
\hline $1064^{*}$ & Crossbred, calf & Kluang, Malaysia & 1974 \\
\hline \multicolumn{4}{|c|}{ Non-pigmented strains } \\
\hline LSN3 & Pond water & Ipoh, Malaysia & 1973 \\
\hline LSN7 & Pond water & Ipoh, Malaysia & 1973 \\
\hline LSN8 & Pond water & Ipoh, Malaysia & 1973 \\
\hline
\end{tabular}

* Strains that yielded non-pigmented variants. The variant is referred to by the same strain number as the parent followed by the letters NP: 609NP, 886NP, 76NP, MDS9NP, 25NP, 6I 7NP and I064NP.

$\dagger$ Five of the ten cases of infection in animals reported by Joseph et al. (I971).

\section{METHODS}

Strains. Eleven pigmented strains of $C$. violaceum from the Veterinary Research Institute's culture collection were used in this study (Table I). Two strains (874 and 916) were no longer viable and therefore data regarding them are limited. Seven of the pigmented strains $(609,886,76$, MDS9, 25, I064 and 6r7) yielded non-pigmented variants. By repeated subculture, pigmented strains were obtained which gave rise only to pigmented colonies and to non-pigmented variants that similarly bred true. In this process it was noticed that nonpigmented variants could yield pigmented, late-pigmenting and non-pigmented colonies. Late-pigmenting colonies first appeared as non-pigmented colonies but, after 3 to 4 days, pigmentation began from the centre and spread to the periphery. They remained pale violet with their periphery unpigmented. Sectored pigmentation was also seen (Fig. I).

The seven non-pigmented variants that were selected could not be induced to pigment using methods said to promote pigmentation, i.e. culturing on potato slopes or mannitol-yeast extract agar (Sneath, 1960; Cowan \& Steel, 1965).

Two pigmented strains ( 17 and 5IO) did not yield non-pigmented variants even after they were subjected to tests reported to inhibit pigmentation (Sneath, I960).

Non-pigmented strains were isolated from ten pond-water samples which were cultured on blood agar plates and incubated at $37^{\circ} \mathrm{C}$. Non-pigmented, haemolytic colonies were screened for $C$. violaceum, and other closely related genera were eliminated in the process. Three non-pigmented cultures were selected for further study. Pigmented strains were not isolated from any of the ten water samples.

Features examined. All the strains (pigmented, their non-pigmented variants, and nonpigmented) were subjected to a series of tests; most tests were adopted from Sneath (I960), but a few others were also used (Cowan \& Steel, I965; Moffett \& Colwell, I968; Ognibene \& Thomas, I970; Bascomb et al. 1973). Some of the media used were prepared from commercially available dehydrated products and therefore the tests and techniques used in their analyses are not completely identical to those of Sneath (1960). His work has been followed closely so that our results and those obtained from his mesophilic strains could be compared. 

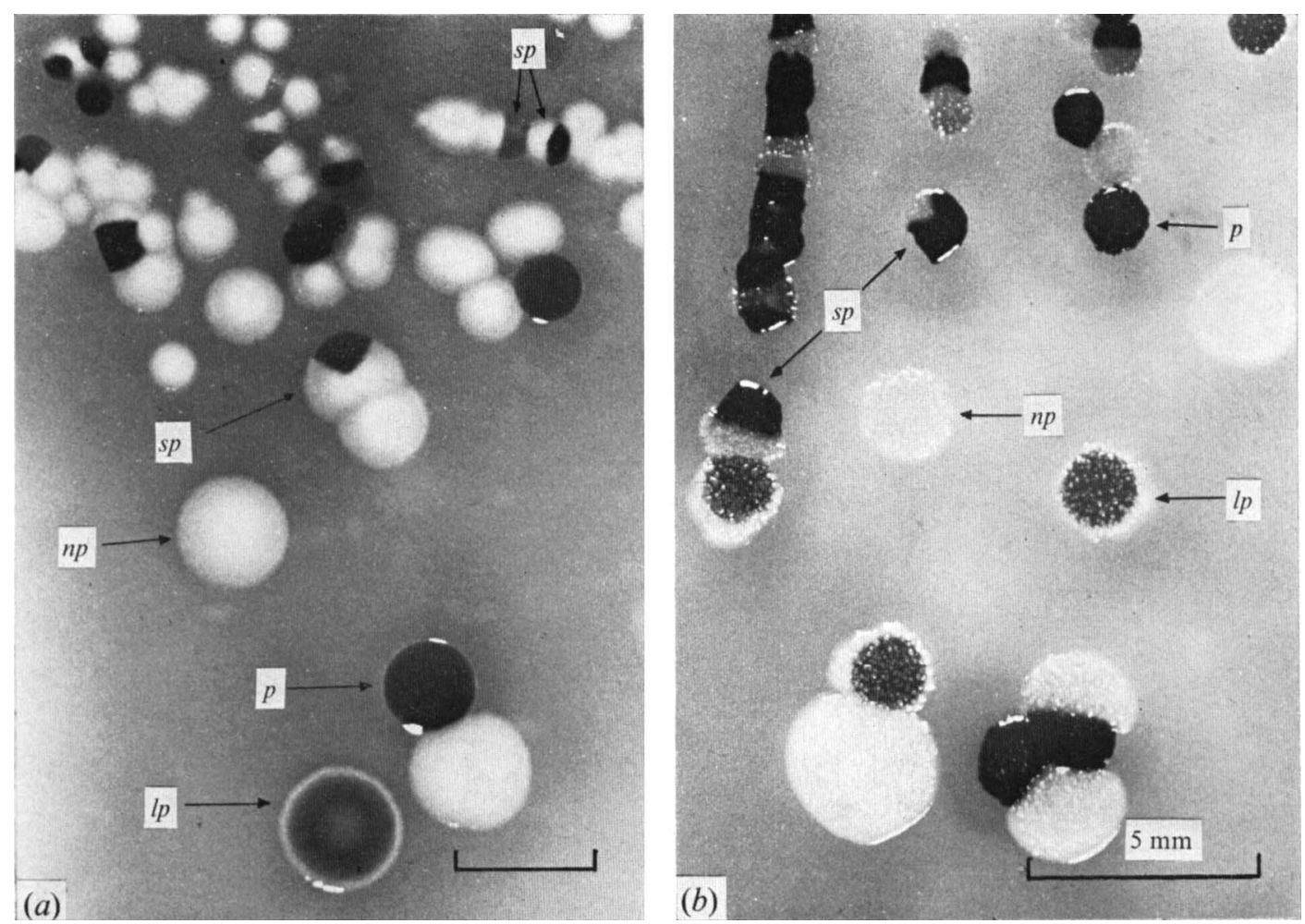

Fig. I. Types of pigmentation. Strains showing pigmented $(p)$, late-pigmenting $(l p)$ and nonpigmented $(n p)$ colonies. Also colonies with sectored pigmentation $(s p)$ are seen. Sizes of pigmented sectors are variable $\left(\frac{1}{4}, \frac{1}{2}, \frac{3}{4}\right.$ sectors are common). Late pigmentation starts after 2 days in strain 886 when colonies are still smooth $(a)$, but much later in strain MDs9, after 4 days, when colonies have become rough $(b)$.

Since he worked with both mesophils and psychrophils, most of his tests were conducted at $25^{\circ} \mathrm{C}$. Our strains were all mesophils and were incubated at $37^{\circ} \mathrm{C}$. Tests were observed daily for 7 days, except where methods required shorter periods of incubation.

Morphological, growth and biochemical studies were conducted according to methods listed in Table 2.

The oxidase test was performed using Kovacs' method (Steel, 196I) or a modification. The oxidase reaction of non-pigmented strains and non-pigmented variants could be tested easily by this method. The reactions of pigmented strains were then assumed to be similar to those of their non-pigmented variants. Pigmented strains that did not yield non-pigmented variants (such as strains 17 and 5IO) could not be tested by the usual procedure (the violet pigmentation interfered with the reading of a positive test) so the method was modified to enable the oxidase reaction of pigmented strains to be determined. The filter paper was soaked with the reagent (tetramethyl-p-phenylenediamine dihydrochloride) on a glass slide. The pigmented strain, a positive control (e.g. Pseudomonas sp.) and a negative control (e.g. Escherichia coli) were smeared adjacent to one another along one edge of the filter paper. When the positive control had reduced the dye (turning it purple), a drop of the reagent was released along the edge of the paper above the culture smears, with the glass slide held at an angle so that reagent flowed over the smears. The reduced dye was washed off the 
Table 2. Morphological, growth and biochemical features examined

Cell morphology

Cell size

Gram stain

Flagella stain (Leifson's 1956 stain modified with $2 \%$ tannic acid)

Colony morphology and dissociation on

Blood agar (ox and horse blood)

MacConkey agar (Difco)

WSTA (Wellcome Reagents)

Growth and biochemical tests

Carbohydrate fermentation reactions examined in peptone water

Litmus milk, reaction

Loeffler's serum medium (LSM), liquefaction

Carbohydrate fermentation reactions examined in Hugh \& Leifson's

(I953) basal medium

Citrate utilization

Malonate utilization

Gelatin liquefaction

$\mathrm{NO}_{3}$ and $\mathrm{NO}_{2}$ reduction

Urease production

Motility

Kligler iron agar (KIA) reaction

Triple sugar iron (TSI) agar reaction

Blood agar, growth

SS agar, growth

Eosin methylene blue (EMB) agar, growth

Indol (Kovacs' reagent)

Methyl red (MR)

Voges Proskauer (VP) (O'Meara's reagent)

Amino acid decarboxylation (Falkow's method)

$\mathrm{KCN}$, growth

Phenylalanine, deamination to phenylpyruvic acid (PPA)

Egg yolk reaction, for lecithinase production

Methylene blue (MB) reduction

$\mathrm{HCN}$ production

$\mathrm{H}_{2} \mathrm{~S}$ production (using lead acetate paper indicator)

Starch hydrolysis

Casein hydrolysis

Aesculin hydrolysis

$\mathrm{NH}_{3}$ production (using Nessler's reagent)

Catalase production

Growth at salt concentrations of $\mathrm{r}$ to $7 \%$ and growth at $\mathrm{pH}$ values from

3 to I I using both nutrient agar and nutrient broth

\} Cruickshank (1965)

$\left\{\begin{array}{l}\text { Using Difco products } \\ \text { Ewing \& Davis (1970) }\end{array}\right.$

Using BBL product

McClung \& Toabe (1947)

\}

surface of the smears and deposited on the filter paper, giving it a purple coloration which constituted a positive test. Alternatively, the oxidase reaction of pigmented strains could be tested using very young cultures ( 15 to $20 \mathrm{~h}$ ) or anaerobic cultures $(24 \mathrm{~h}$ ) in which their pigmentation was reduced or inhibited.

The sensitivity patterns to antimicrobial agents of the pigmented strains and their variants, and of non-pigmented strains, were studied using DST agar (Oxoid) plates inoculated from $24 \mathrm{~h}$ broth cultures with a cotton swab. Inhibition zone diameters (in centimetres) were measured after overnight incubation. Oxoid Multodisks (Nos. I788 E and $1789 \mathrm{E}$ ) were used with the following antimicrobial agents: septrin (SXT), $25 \mu \mathrm{g}$; ampicillin (PN), $25 \mu \mathrm{g}$; chloramphenicol (C), Io $\mu \mathrm{g}$; cloxacillin (OB), $5 \mu \mathrm{g}$; erythromycin (E), $10 \mu \mathrm{g}$; penicillin $\mathrm{G}$ 
Table 3. Carbohydrate fermentation

\section{Cultures}

Pigmented strains

Non-pigmented variants

Non-pigmented strains

From Sneath (1960)
In peptone water

Carbohydrates utilized:

Glucose, fructose, mannose and trehalose

Carbohydrates not utilized:

Maltose, sorbitol, glycerol, galactose, arabinose, xylose, rhamnose, lactose, raffinose, inulin, adonitol, mannitol, dulcitol, inositol, salicin, and aesculin

Variable reactions obtained with:

Sucrose $(7 / \mathrm{II}),{ }^{*}$ starch $(\mathrm{I} / \mathrm{I} \mathrm{I})^{*}$ and dextrin $(9 / \mathrm{II})^{*}$

Reactions identical to parent strains

Reactions similar to pigmented strains except that all three strains did not utilize mannose and sucrose. Dextrin was utilized but not starch

His I4 strains produced results similar to our pigmented strains
In Hugh and Leifson's basal medium

Carbohydrates fermented: Glucose, fructose, mannose, trehalose and dextrin

Carbohydrates not fermented: Galactose, arabinose, xylose, lactose, maltose, inulin, glycerol, mannitol, dulcitol, sorbitol, inositol and salicin

Variable reactions obtained with: Sucrose $(5 / 9)^{*}$ and starch $(3 / 9)^{*}$

Reactions identical to parent strains

Reactions similar to pigmented strains except that all three strains did not ferment mannose and sucrose. Starch was not fermented

Results were obtained with 14 strains for some carbohydrates and 15 for others. His results are similar to our pigmented strains except for sorbitol (I2/I4)* and glycerol (5 strains gave oxidative reactions)

* Number of positive reactions/total number of strains tested.

(P), I.5 units; streptomycin (S), $25 \mu \mathrm{g}$; tetracycline (TE), $50 \mu \mathrm{g}$; colistin (CS), $200 \mu \mathrm{g}$; nalidixic acid (NA), $30 \mu \mathrm{g}$; nitrofurantoin (F), $200 \mu \mathrm{g}$; and compound sulphonamide $\left(\mathrm{S}_{3}\right)$, $300 \mu \mathrm{g}$.

\section{RESULTS AND DISCUSSION}

Carbohydrate fermentation and biochemical tests. The results of these tests are shown in Tables 3 and 4. Carbohydrate utilization was fermentative without gas production. All our strains utilized dextrin fermentatively, a character not previously reported by Sneath (I 956 a, I960) or other workers. Two of Moffett \& Colwell's (I 968) carbohydrate fermentation reactions differed from Sneath's (1960) and our results: Moffett and Colwell found that one strain produced acid from sorbitol and another did not attack trehalose.

The carbohydrate fermentation activities in peptone water of all strains correlated well with reactions in the Hugh \& Leifson (1953) medium, Kligler iron agar (KIA) and in triple sugar iron (TSI) agar. The fermentation of starch by strains $76,76 \mathrm{NP}, 6 \mathrm{I} 7,6 \mathrm{I} 7 \mathrm{NP}, 1064$ and I064NP, and the fermentation of dextrin by strains 6I7, 6I 7NP, I064 and I064NP were exceptions: acid was produced in the Hugh and Leifson medium but not in the medium based on peptone water. This could be due to a more sensitive indication of acidity by bromothymol blue (at pH 6) than Andrade's indicator (at pH 5). All strains fermented glucose but not lactose. Sucrose was only utilized by some strains. This pattern of carbohydrate fermentation was reflected in the reactions on KIA and TSI agar. Strains that fermented only glucose produced an acid butt and no change in the slant in both KIA and TSI agar. Strains that attacked glucose and sucrose produced acidity in the slant and butt of the TSI agar. In this respect, the TSI agar results of Ognibene \& Thomas (1970) are not consistent with the fermentative abilities of their strains. 
Table 4. Growth and biochemical characteristics

\begin{tabular}{|c|c|c|c|}
\hline \multicolumn{4}{|l|}{ Pigmented strains } \\
\hline Indole & \multicolumn{3}{|c|}{ Hydrolysis of } \\
\hline MR & - & Starch & - \\
\hline VP & - & Casein & + \\
\hline Catalase & + & Gelatin & + \\
\hline Oxidase & + & Aesculin & - \\
\hline Haemolysis & + & & \\
\hline Motility & + & Reduction of & \\
\hline Egg yolk & + & MB & + \\
\hline LSM & + & $\mathrm{NO}_{3}$ & + \\
\hline Litmus milk & + & $\mathrm{NO}_{2}$ & - \\
\hline $\mathrm{KCN}$ & \pm & & \\
\hline SS agar & $\mp(2 / 9) \dagger$ & Production of & \\
\hline EMB agar & + & $\mathrm{HCN}$ & + \\
\hline MacConkey agar & + & $\mathrm{H}_{2} \mathrm{~S}$ & - \\
\hline Growth, $37^{\circ} \mathrm{C}, 24 \mathrm{~h}$ & + & PPA & - \\
\hline Growth, $4{ }^{\circ} \mathrm{C}, 7$ days & - & $\mathrm{NH}_{3}$ & + \\
\hline KIA & $\mathbf{K} / \mathbf{A}^{*}$ & Urease & \\
\hline TSI & $\mathrm{K} / \mathrm{A}$ or $\mathrm{A} / \mathrm{A}^{*}$ & \multicolumn{2}{|l|}{ Decarboxylation of } \\
\hline \multicolumn{2}{|l|}{ Utilization of } & Lysine & \multirow{3}{*}{$\overline{+}$} \\
\hline Citrate & $\pm(7 / \mathbf{I}) \dagger$ & Arginine & \\
\hline Malonate & - & Ornithine & \\
\hline & \multicolumn{3}{|c|}{$\begin{array}{l}\text { Non-pigmented variants } \\
\text { Reactions identical to parent strains }\end{array}$} \\
\hline \multicolumn{4}{|c|}{$\begin{array}{l}\text { Non-pigmented strains } \\
\text { Reactions similar to pigmented strains. Strain LSN8 utilized citrate but LSN3 and LSN7 did not. }\end{array}$} \\
\hline \multicolumn{4}{|c|}{$\begin{array}{l}\text { Sneath }(1960) \\
\text { Results were obtained for } 14 \text { strains for some tests and } 15 \text { for others. He had performed all tests except for } \\
\text { oxidase, KCN, SS, EMB, KIA, TSI, citrate, lysine, arginine and ornithine. His results are in agreement with } \\
\text { our pigmented strains except for } \mathrm{NO}_{3} \text { reduction }(\mathrm{I} 4 / 15) \dagger, \mathrm{NO}_{2} \text { reduction (I2/14) } \dagger \text { and starch hydrolysis } \\
(2 / 15) \dagger\end{array}$} \\
\hline
\end{tabular}

For abbreviations, see Table 2.

${ }^{*} \mathrm{~K}$, alkaline; A, acid; $\mathrm{H}_{2} \mathrm{~S}$ and gas were not detected. Results are expressed as the ratios of the reaction on the slant to the reaction in the butt.

$\uparrow$ Number of positive reactions/total number of strains tested.

Our strains reduced nitrate to nitrite, but nitrite was not reduced further even after incubation for 7 days. Sneath (I960) found nearly all his strains reduced nitrite which he attributed (personal communication) to having such a low concentration of nitrite in his medium that even a weak reduction could be detected.

Some of our strains utilized citrate, two strains grew on SS agar (Difco) and all on eosin methylene blue (EMB) agar (moderately only), whereas all four strains of Ognibene \& Thomas (I970) utilized citrate and grew on SS and EMB agars. Laws \& Hall (1958) obtained no growth on SS agar with their four strains. Our results for the decarboxylation of lysine, arginine and ornithine agree with those of Cowan \& Steel (I965) and Moffett \& Colwell (1968).

Almost all strains gave strong catalase reactions, but a few strains were slow, reacting only after a few seconds, and the production of gas bubbles was moderate. All non-pigmented strains and non-pigmented variants gave strong oxidase reactions. Our modified method was successful in obtaining positive reactions from pigmented strains. Ognibene \& Thomas (1970) reported oxidase-positive reactions with their strains. Bascomb et al. (1973) have accepted both $C$. violaceum and $C$. lividum as oxidase-positive in their matrix for the 
identification of selected bacteria by computer, while Moffett \& Colwell (I968) state that $C$. violaceum is oxidase-positive and $C$. lividum variable. Sneath now accepts $C$. violaceum as oxidase-positive and $C$. lividum as moderately positive, with quite a number of strains giving equivocal results (personal communication), although he had not reported on this character earlier.

Steel (196I) and Lapage et al. (1973) have commented that the oxidase reaction of Chromobacterium species cannot be determined by methods that depend on the production of a violet colour. Steel (196I) conducted tests with non-pigmented colonies and young cultures (before pigmentation was well developed) of six strains, and found them to be oxidase-negative. Cowan \& Steel (1965), Isenberg \& Berkman (I966) and Lowis (I97I) have constructed diagnostic tables, keys and schemes for the identification of bacteria with the genus Chromobacterium designated as oxidase-negative. These will now have to be amended since the positive oxidase activity of Chromobacterium has been firmly established.

The carbohydrate fermentation and biochemical reactions of the pigmented strains are identical with their variants, although in general the activities of the non-pigmented variants are less intensive than those of their pigmented parents.

Sensitivity patterns. A remarkable degree of uniformity is shown by the strains in their sensitivities to antimicrobial agents, a fact which can be profitably used in the identification of $C$. violaceum, particularly the non-pigmented strains. The following antimicrobial agents (see Methods for abbreviations) gave consistent results (either large zones of inhibition, in which case the average diameter of the inhibition zone is given in parentheses, or no zones, i.e. resistant): C $(2 \mathrm{~cm}), \mathrm{E}(2 \mathrm{~cm}), \mathrm{TE}(2.8 \mathrm{~cm}), \mathrm{NA}(3 \mathrm{~cm}), \mathrm{F}(3 \mathrm{~cm}), \mathrm{PN}$ (resistant), P (resistant) and $\mathrm{OB}$ (resistant). The following agents gave inconsistent results: $\mathbf{S}$ and $\mathrm{CS}$ (small or no zones); SXT and $\mathrm{S}_{3}$ (large zones of up to $3 \mathrm{~cm}$, but inhibition was partial).

Tolerance of sodium chloride and $\mathrm{pH}$ value for growth. Most strains could tolerate only up to $3 \%(\mathrm{w} / \mathrm{v}) \mathrm{NaCl}$ but a few could grow in $5 \%(\mathrm{w} / \mathrm{v}) \mathrm{NaCl}$. All strains grew at $\mathrm{pH}$ values from 5 to 9 , and some at $\mathrm{pH}$ values of 4 , IO and $\mathrm{I}$; none grew at $\mathrm{pH} 3$.

The $\mathrm{NaCl}$ tolerance and $\mathrm{pH}$ value for growth of the non-pigmented strains were within the limits set by our pigmented strains and their variants, and the strains of Sneath. The seven strains of Moffett \& Colwell (I968) did not grow in $3 \%(\mathrm{w} / \mathrm{v}) \mathrm{NaCl}$, but their $\mathrm{pH}$ values for growth were similar to ours.

Microscopic morphology. All strains stained Gram-negative and measured approximately $0.5^{-\mathrm{I}} \times 2^{-}-3 \mu \mathrm{m}$. Smaller and larger rods were occasionally seen.

All strains showed the characteristic flagella morphology of Chromobacterium (Leifson, I956; Sneath, I956b) (Fig. 2). Sometimes bacteria were observed with flagella that were straight or slightly curved but with no waves, and such findings have not been previously reported (Leifson, 1956; Sneath, 1956b). The occurrence of these atypical forms of flagellation was so rare that it should not lead to confusion in the identification of C. violaceum (Fig. 3 ).

Macroscopic morphology. All strains were fairly uniform in their colonial appearance on blood agar plates after incubation for $24 \mathrm{~h}$ at $37^{\circ} \mathrm{C}$. They produced colonies that were smooth, round, shiny and slightly convex. The colonies ranged from $\mathrm{I} \cdot 5$ to $2 \cdot 0 \mathrm{~mm}$ in diameter, and if pigmented were purple or black. Strains differed in their haemolytic activities, some strains producing small zones of haemolysis that were hardly visible outside the colony while others produced large zones up to $4 \mathrm{~mm}$ in diameter.

On prolonged incubation at room temperature, the strains exhibited great variations in colony sizes and types of rough forms (Fig. 4). Some strains produced double-zoned haemolysis. The strains Sneath examined did not show such haemolysis (personal communication) and other workers have not commented on it. 

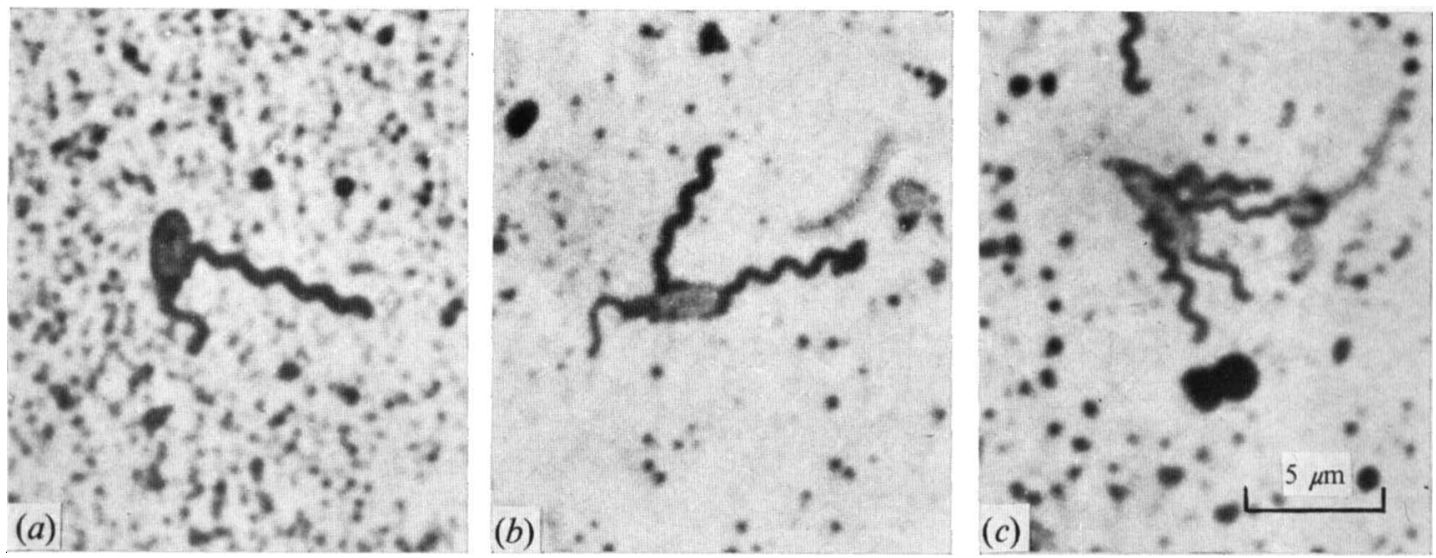

Fig. 2. Typical flagella morphology. A single, short, polar flagellum and a few long, lateral (or subpolar) flagella. Lateral flagella have shorter wavelengths and stain better than polar flagella. (a) Strain 609; (b) and (c) strain LSN7.
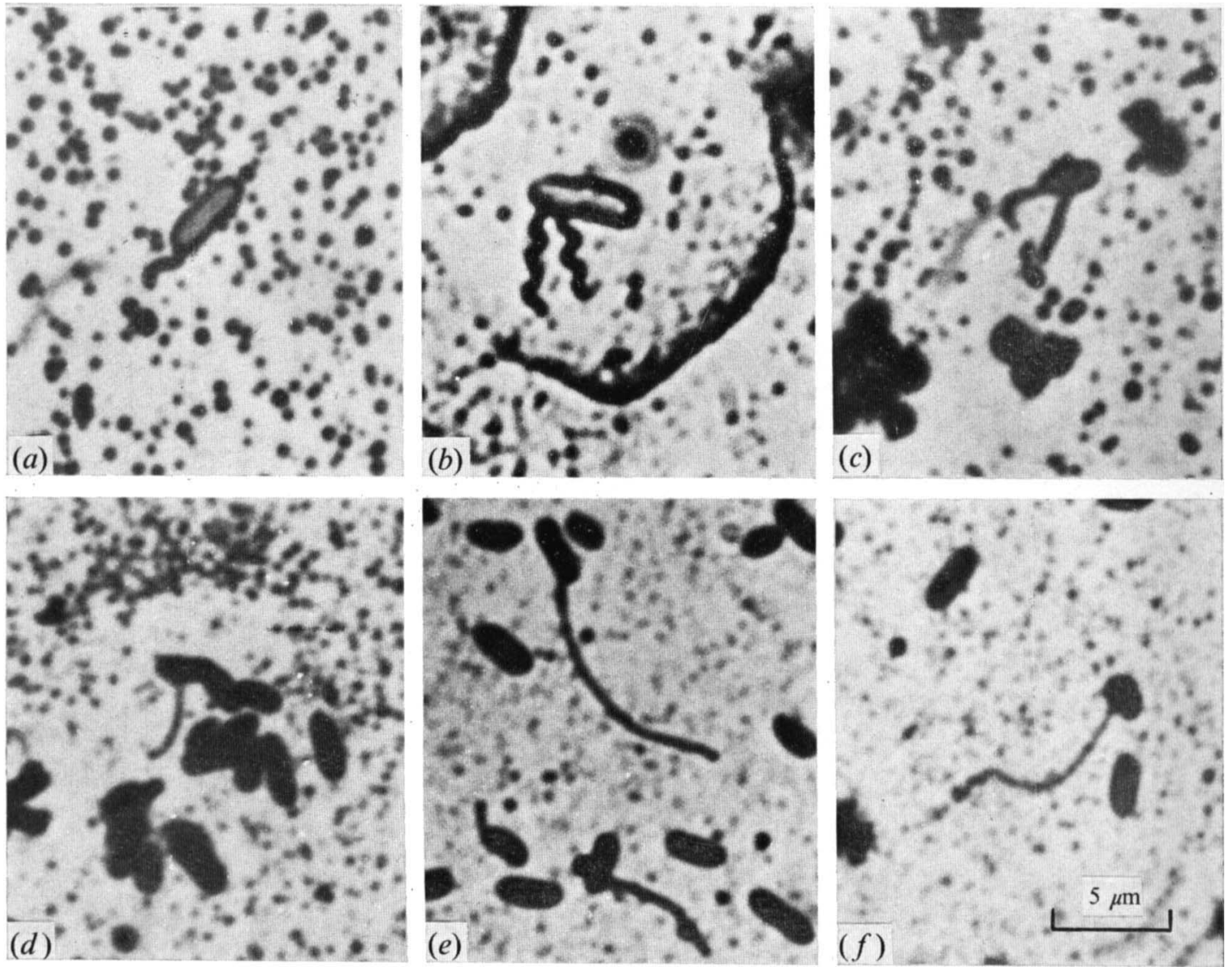

Fig. 3. Atypical flagella morphology. Cells with only polar, or only lateral, or with straight flagella. (a) Strain 886NP; (b) strain LSN3; (c) strain 510; (d) strain MDS9NP; $(e)$ strain $76 ;(f)$ strain MDS9NP. 

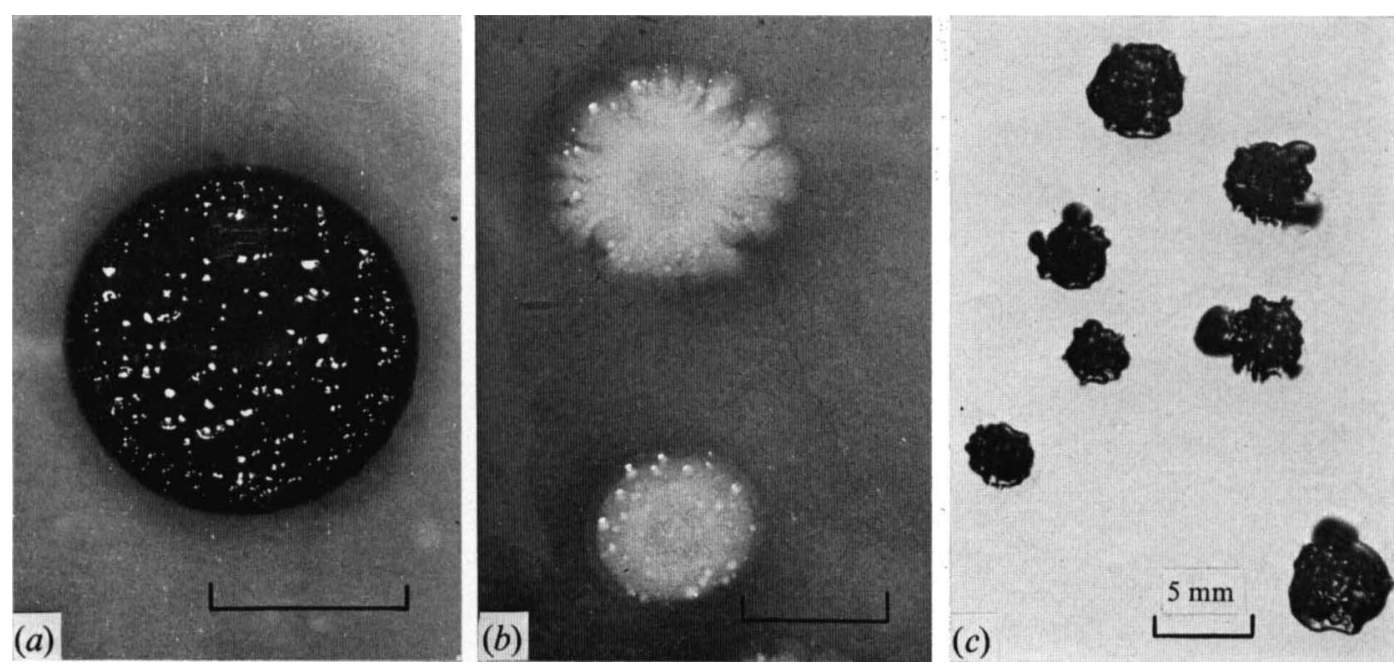

Fig. 4. Dissociant colonial types. (a) Colony circular with rough surface; strain 76,7 days. (b) Spreading rough colonies; strain 609NP, 7 days. (c) Irregular colonies with loss of all original features; strain 916, 7 days.

Non-pigmented colonies were initially grey in colour but became brown within 3 days. Their dissociant behaviour was similar to that of pigmented strains.

When these rough forms were subcultured they became smooth again. It appears, therefore, that the smooth-rough transformation is a dissociation that is simply a function of age and environment.

Sneath conducted his morphological studies on horse-blood agar plates but we used both ox- and horse-blood agar plates and obtained identical results. On MacConkey agar all strains grew well and their colonies were morphologically similar to those on blood agar plates. All strains gave relatively mucoid colonies on WSTA (Wellcome Reagents).

Peptone water cultures produced a ring of growth, and after 3 days a surface pellicle was formed with the pigmented cultures being visibly violet.

\section{CONCLUSIONS}

The isolation from ponds of non-pigmented bacteria that resemble $C$. violaceum in all growth, morphological and biochemical characteristics is evidence of the wide distribution in nature of $C$. violaceum. These non-pigmented $C$. violaceum strains could not be induced to produce pigment. Thus, pigmentation is not an essential characteristic in the definition of the genus Chromobacterium and should not be given undue emphasis in identification. Weighting of characteristics often used in conventional identification, whereby fermentative, violet-pigmented organisms are considered to be $C$. violaceum, has been criticized by Bascomb et al. (1973). Moffett \& Colwell (I968) noticed that the pigmentation of their strains was not stable and therefore excluded pigment description from their tables.

Nineteen cases of $C$. violaceum infection in man and 17 reports in animals are referred to by Sneath (1960), Wijewanta \& Wettimuny (1969), Johnson, DiSalvo \& Steuer (I97I) and Joseph et al. (I97I). Diagnostic bacteriologists should also consider C. violaceum in the identification of non-pigmented Gram-negative bacilli and treat it as a potential pathogen. It is likely that non-pigmented strains of $C$. violaceum have been dismissed as laboratory 
contaminants, or wrongly identified and reported as belonging to other genera, particularly to those that are also widely distributed in soil and water: Aeromonas, Pseudomonas, Vibrio, Agrobacterium, Achromobacter, Xanthomonas and Flavobacterium. The tests described in this paper are sufficient to eliminate these other genera and to give a positive identification for C. violaceum.

Sneath (1960) reported that non-pigmented variants of $C$. lividum arise in culture. It is likely, therefore, that non-pigmented strains of $C$. lividum can also be isolated from nature.

We thank Professor P. H. A. Sneath, Director of the Medical Research Council Microbial Systematics Unit, Leicester University, for assisting in the preparation of this manuscript, Mr H. K. Loo and Mr P. H. Leong for technical assistance, and Mr S. W. Liew for assisting with photography. We are also grateful to Dr M. Fadzil, Director of the Veterinary Research Institute, Malaysia, for providing access to the Institute's culture collection and to the Director-General of Veterinary Services, Peninsular Malaysia, for permission to publish this paper.

\section{REFERENCES}

Bascomb, S., Lapage, S. P., CurTis, M. A. \& Willcox, W. R. (1973). Identification of bacteria by computer: identification of reference strains. Journal of General Microbiology 77, 29 I-315.

Bergey's Manual, of Determinative Bacteriology, 7th edn (1957). Edited by R. S. Breed, E. G. D. Murray and N. R. Smith. Baltimore: Williams and Wilkins.

CowAN, S. T. \& SteeL, K. J. (1965). Manual for the Identification of Medical Bacteria. Cambridge University Press.

Cruickshank, R. (1965). Medical Microbiology, i Ith edn. Edinburgh: E. and S. Livingstone.

EwING, W. H. \& DAvis, B. R. (1970). Media and Tests for Differentiation of Enterobacteriaceae. Atlanta, Georgia: U.S. National Communicable Disease Center.

Hugh, R. \& LeIfson, E. (1953). The taxonomic significance of fermentative versus oxidative metabolism of carbohydrates by various Gram-negative bacteria. Journal of Bacteriology 66, 24-26.

IsENBERG, H. D. \& BERKMAN, J. I. (1966). Recent practices in diagnostic bacteriology. In Progress in Clinical Pathology, vol. I, pp. 237-317. Edited by M. Stefanini. New York: Grune and Stratton.

Johnson, W. M., DiSalvo, A. F. \& Steuer, R. R. (1971). Fatal Chromobacterium violaceum septicemia. American Journal of Clinical Pathology 56, 400-406.

Joseph, P. G., SiVendra, R., ANWAR, M. \& ONG, S. F. (1971). Chromobacterium violaceum infection in animals. Kajian Veterinaire, Malaysia-Singapore 3, 55-66.

Judicial Commission (1958). Opinion 16. In International Bulletin of Bacteriological Nomenclature and Taxonomy 8, 151-152.

Lapage, S. P., Bascomb, S., Willcox, W. R. \& CuRTis, M. A. (1973). Identification of bacteria by computer: general aspects and perspectives. Journal of General Microbiology 77, 273-290.

Laws, L. \& HALL, W. T. K. (1958). Chromobacterium violaceum infection in a pig. Queensland Journal of Agricultural and Animal Science 15, 145-149.

Lerrson, E. (1956). Morphological and physiological characteristics of the genus Chromobacterium. Journal of Bacteriology 7x, 393-400.

LowIS, M. J. (197 I). An identification key for some aerobic bacteria. Laboratory Practice 20, 33 I-333.

MCClúNG, L. S. \& TOABE, R. (1947). Egg yolk plate reaction for presumptive diagnosis of Clostridium sporogenes and certain species of gangrene and botulinum group. Journal of Bacteriology 53, I39-147.

Moffert, M. L. \& Colwell, R. R. (1968). Adansonian analysis of the Rhizobiaceae. Journal of General Microbiology 51, 245-266.

Ognibene, A. J. \& ThOmas, E. (1970). Fatal infection due to Chromobacterium violaceum in Vietnam. American Journal of Clinical Pathology 54, 607-610.

SNEATH, P. H. A. (1956a). Cultural and biochemical characteristics of the genus Chromobacterium. Journal of General Microbiology 15, 70-98.

SNEATH, P. H. A. $(1956 b)$. The change from polar to peritrichous flagellation in Chromobacterium spp. Journal of General Microbiology 15, 99-105.

SNeAth, P. H. A. (1956c). Conservation of the generic name Chromobacterium and designation of type species and type strains. International Bulletin of Bacteriological Nomenclature and Taxonomy 6, 65-9I. 
SNEATH, P. H. A. (1960). A study of the bacterial genus Chromobacterium. Iowa State Journal of Science 34, 243-500.

SNEATH, P. H. A. (1966). Identification methods applied to Chromobacterium. In Identification Methods for Microbiologists A, pp. 15-20. Edited by B. M. Gibbs and F. A. Skinner. Society for Applied Bacteriology Technical Series, No. I. London: Academic Press.

SNeath, P. H. A., Whelan, J. P. F., Singh, R. B. \& Edwards, D. (1953). Fatal infection by Chromobacterium violaceum. Lancet ii, 276-277.

Steel, K. J. (I96I). The oxidase reaction as a taxonomic tool. Journal of General Microbiology 25, 297-306.

Wijewanta, E. A. \& Wettimuny, S. G. De S. (1969). Chromobacterium violaceum infection in pigs. Research in Veterinary Science 10, 389-390. 